\title{
A study of infectious intestinal disease in England: risk factors associated with group A rotavirus in children
}

\author{
D. SETHI ${ }^{1 *}$, P. CUMBERLAND ${ }^{1}$, M. J. HUDSON ${ }^{2}$, L. C. RODRIGUES ${ }^{1}$, \\ J. G. WHEELER ${ }^{1}$, J. A. ROBERTS ${ }^{1}$, D. S. TOMPKINS ${ }^{3}$, J. M. COWDEN ${ }^{4}$ \\ AND P.J. RODERICK ${ }^{5}$ \\ ${ }^{1}$ London School of Hygiene and Tropical Medicine, Keppel Street, London WC1E 7HT, England \\ ${ }^{2}$ Centre for Applied Microbiology and Research, Ponton Down, Salisbury, Wiltshire, UK \\ ${ }^{3}$ Leeds Public Health Laboratory, York Road, Leeds, UK \\ ${ }^{4}$ Scottish Centre for Infection and Environmental Health, Clifton Place, Glasgow, UK \\ ${ }^{5}$ Southampton University, Southampton, UK
}

(Accepted 1 January 2000)

\section{SUMMARY}

Objective: To identify risk factors for infectious intestinal disease (IID) due to rotavirus group A in children aged under 16 years.

Methods: Case-control study of cases of IID with rotavirus infection presenting to general practitioners (GPs) or occurring in community cohorts, and matched controls.

Results: There were 139 matched pairs. In children under 16 years the following risk factors were significantly associated with rotavirus IID: living in rented council housing (adjusted $\mathrm{OR}=3.78, P=0.022)$, accommodation with more than five rooms $(\mathrm{OR}=0.72, P=0.002)$, contact with someone ill with IID (OR $=3 \cdot 45, P<0 \cdot 001)$. Some foods were associated with decreased risk. In infants, bottle feeding with or without breast feeding was associated with increased risk $(\mathrm{OR}=9 \cdot 06, P<0 \cdot 05)$.

Conclusions: Contact with persons with IID, living in rented council housing and accommodation with fewer rooms, were significant risk factors for sporadic rotavirus IID in children whereas breast feeding is protective in infants.

\section{INTRODUCTION}

More than 140 million children worldwide develop rotavirus gastro-enteritis each year. It is the leading cause of childhood diarrhoeal deaths in low- and middle-income countries, claiming about 600000 and 800000 lives annually [1-3]. In contrast mortality in high income countries is very low and mainly arises during the winter epidemics [4]. Nevertheless rotavirus is the leading cause of hospitalization due to diarrhoeal illness, accounting for about a third of such admissions worldwide [5]. In England and Wales over half the admissions for infectious intestinal disease were attributable to rotavirus [6]. The study of

* Author for correspondence. infectious intestinal disease (IID) in England found rotavirus group A to be the most common cause of IID in children under 5 years old presenting to the GP. Rotavirus infection was very common in the community [7]. Infection with rotavirus is associated with high costs both to the health service and to the family [8].

There are few studies which describe risk factors associated with community acquired rotavirus infection. Those that do, have identified attendance at child-care facilities [9], exposure to other children with diarrhoea and poor sanitation as risk factors [10]. Also, socio-economic deprivation, such as overcrowding, low maternal education, and having been born of low birth weight were significant factors in 
children presenting to outpatient clinics [11]. The study of IID in England therefore presented an opportunity to examine risk factors for infection, in cases that did not necessarily present to the GP, in a large representative population [12]. Rotavirus, unlike many of the organisms which cause IID are not thought to be foodborne. A report on foodborne viral infections in the United Kingdom found that of 53 outbreaks of rotavirus only one was foodborne [13]. Spread is believed to be faecal oral, through respiratory secretions, person-to-person contact and contaminated environmental surfaces [5]. Breast feeding is thought to confer protection against gastrointestinal pathogens, in particular bacteria $[14,15]$, but there are conflicting results as to rotavirus infection: some authors found no protection $[14,16]$ others have found some protection [17], and others evidence that breast feeding offers protection against severe infection only [18].

The aim of this paper is to investigate risk factors of community acquired rotavirus IID in infants and children under 16 years of age, not all of whom presented to their GP. Existing hypotheses for rotavirus infection in this age group were also tested.

\section{METHODS}

This study reports on the investigation of potential risk factors for IID with rotavirus infection in cases from the community and presenting to GPs during a large study of infectious intestinal disease (IID) in England [12]. Seventy general practices were volunteers selected from the Medical Research Council's general practice research framework to meet specific criteria [12]. Data were collected between 1993 and 1996. Practice recruitment was staggered over 18 months and each practice collected data for one year. All 70 took part in the community case-control component in which two cohorts were recruited from each practice and followed for 6 months. An average of 140 people were recruited per practice. Of the 70 practices, 34 took part in the GP case-control component. The case definition of IID used in the study was: persons with loose stools or significant vomiting lasting less than 2 weeks, in the absence of a known non-infectious cause and preceded by a symptom free period of 3 weeks. Controls were eligible if they had been free of loose stools or significant vomiting for 3 weeks. All cases of IID had a stool examination requested, including those not presenting to a GP, and those presenting to a GP who would not under routine conditions have had a stool investigation. The objectives, methods used, details of ethics approval and initial results have been described fully elsewhere $[7,12,19,20]$. Cases and controls presented in this paper were from the community and GP components of the above study.

In the GP component cases under 16 years of age presenting with IID were recruited into the study, their parent or guardian was asked to complete a risk factor questionnaire, and a stool sample was posted to Leeds Public Health Laboratory (PHL) where samples were tested for a comprehensive range of organisms, including rotavirus. The questionnaire had items on social factors, accommodation, travel, contact with persons with IID and food. The questionnaire was completed before the results of the stool investigations were known, and so the same questionnaire was used for cases of IID with rotavirus infection as for all cases of IID. Information was obtained on a large number of variables but only those suspected a priori to be associated with rotavirus infection were analysed. This was to reproduce the more common situation where a questionnaire is developed to investigate a single infection, and includes only questions about the factors suspected to be associated with that infection. By concentrating on these variables, we also reduced multiple testing.

Age- and sex-matched controls were selected from the practice's register and underwent identical procedures. Data were collected in the same way for cases and their matched controls in the community casecontrol study [19]. Cases were considered to have rotavirus group $\mathrm{A}$ if a positive identification of the virus was made in the stool sample using a standard enzyme linked immunosorbent assay (ELISA) [7]. Data on cases and controls from the two components were analysed together.

\section{Statistical analysis}

A matched case-control analysis was carried out on 139 pairs aged under 16 years in whom both the case and control had answered a risk factor questionnaire. Analysis was carried out using STATA [21]. Variables suspected to be associated with risk of rotavirus infection on the basis of prior hypotheses were analysed. For children under 16 years this included social class, travel, swimming, accommodation, food, and contact with persons with IID (Table 1); for children under 5 years attendance at child care; and for infants, feeding practice. As not all cases of IID with rotavirus infection had a control, additional controls meeting matching criteria of practice, age, 
Table 1. Variables included in univariate analysis for children under

16 years

\begin{tabular}{|c|c|}
\hline Social factors & Social class \\
\hline \multicolumn{2}{|l|}{ Indirect factors } \\
\hline \multirow[t]{2}{*}{ Travel and water sports } & Travel \\
\hline & Swimming and water sports \\
\hline \multirow[t]{3}{*}{ Accommodation } & Detached/semi/terraced property \\
\hline & Ownership of property \\
\hline & Number of rooms in household \\
\hline \multicolumn{2}{|l|}{ Direct factors } \\
\hline Contact & Contact with ill person \\
\hline \multirow[t]{9}{*}{ Foods } & Fish (oily/non-oily) \\
\hline & Prawns \\
\hline & $\begin{array}{l}\text { Chicken (home/restaurant, fresh/frozen, giblets/no } \\
\text { giblets) }\end{array}$ \\
\hline & Meat (pork/lamb/cold meats) \\
\hline & Eggs \\
\hline & Pasteurized products \\
\hline & Salad (home/restaurant) \\
\hline & Fruit (skin/skinless/dried) \\
\hline & Pulses \\
\hline
\end{tabular}

sex and season, were selected at random from those controls matched to cases of IID with other infections. These additional controls comprised less than $10 \%$ of all controls. Analysis was initially univariate, and then adjusted for accommodation factors (owned, rented private, rented council, number of rooms in the household) and contact with persons with IID and food consumption. This approach employed a conceptual framework of how risk factors influenced the development of IID: social class, intermediate factors thought to have an indirect affect on being exposed to rotavirus (e.g. accommodation, travel), and direct factors such as contact with a person with IID or food consumption. Factors which were not significant in the univariate analysis were not included in the subsequent models when adjustments were made. To allow for the possibility that chance associations may be found due to multiple testing, these were only considered significant at less than the $1 \%$ level. Associations between a $1 \%$ and $5 \%$ level of significance were regarded as borderline and are also reported. The analysis in infants was initially univariate, then adjusted for contact with persons with IID only, as numbers were small. In this instance associations were taken as significant at the $5 \%$ level as there was no multiple testing. Population attributable fractions (PAF) were calculated using the formula:

$\mathrm{PAF}=P^{\prime} \frac{(\mathrm{OR}-1)}{\mathrm{OR}}$ where $P^{\prime}=$ proportion of cases in the exposed group; $\mathrm{OR}=$ odds ratio.

\section{RESULTS}

\section{Data collected}

The age distribution of all cases and controls under the age of 16 years whose stool were tested for rotavirus is presented in Table 2 . Of these, data are presented on the 139 matched pairs in whom both the case and control had answered a risk factor questionnaire. $12 \%$ of the pairs were from the community component. 123 pairs were under 5 years of age, including 39 infants. There was a median delay of 24 days between the recruitment of cases and of their controls; $60 \%$ of controls were recruited within 1 month of their case, and $80 \%$ within 2 months. The distribution of cases peaked between the months of January and April.

\section{Risk factors for children under $\mathbf{1 6}$ years of age}

There was no statistically significant association between social class and rotavirus infection $(\mathrm{OR}=$ $1 \cdot 2 ; 95 \% \mathrm{CI}, 0 \cdot 71-2 \cdot 04$, for manual vs. non-manual class, $P=0 \cdot 5$ ). However a significant association was found between the type of accommodation and rotavirus infection (Table 3). Living in rented council accommodation increased the risk fivefold and living 
Table 2. Age distribution of cases and their controls tested for group A rotavirus and the numbers identified

\begin{tabular}{|c|c|c|c|c|c|}
\hline \multirow[b]{2}{*}{$\begin{array}{l}\text { Age } \\
\text { (years) }\end{array}$} & \multicolumn{2}{|l|}{ Cases } & \multicolumn{2}{|l|}{ Controls } & \multirow[b]{2}{*}{$\begin{array}{l}\text { Matched pairs analysed } \\
\text { (\% of total pairs) }\end{array}$} \\
\hline & $\begin{array}{l}\text { Number and percent }(\%) \\
\text { rotavirus identified }\end{array}$ & $\begin{array}{l}\text { Number } \\
\text { tested }\end{array}$ & $\begin{array}{l}\text { Number and percent }(\%) \\
\text { rotavirus identified }\end{array}$ & $\begin{array}{l}\text { Number } \\
\text { tested }\end{array}$ & \\
\hline Under 1 & $59(20 \cdot 2)$ & 292 & $3(1 \cdot 2)$ & 245 & $39(28 \cdot 1)$ \\
\hline $1-4$ & $111(15 \cdot 5)$ & 715 & $4(0 \cdot 6)$ & 659 & $84(60 \cdot 4)$ \\
\hline $5-15$ & $19(6 \cdot 0)$ & 319 & 0 & 276 & $16(11 \cdot 5)$ \\
\hline Total & $189(14 \cdot 3)$ & 1326 & $7(0 \cdot 6)$ & 1180 & $139(100)$ \\
\hline
\end{tabular}

Table 3. Risk factors for IID with rotavirus group $A$ in stools in people under 16 years of age, with OR, $95 \%$ $C I$ and $P$ values, univariate, adjusted for accommodation factors and contact with another person with IID. Only factors which remain statistically significant in the adjusted models are shown

\begin{tabular}{|c|c|c|c|c|c|c|c|c|c|c|}
\hline & \multirow{2}{*}{$\frac{\text { Controls }}{(n=139)}$} & \multirow{2}{*}{$\frac{\text { Cases }}{(n=139)}$} & \multicolumn{4}{|c|}{ Unadjusted } & \multicolumn{4}{|c|}{ Adjusted } \\
\hline & & & OR & $95 \%$ & $\mathrm{CI}$ & $P$ value & OR & $95 \%$ & $\mathrm{CI}$ & $P$ value \\
\hline \multirow{2}{*}{\multicolumn{2}{|c|}{$\begin{array}{l}\text { Indirect risk factors } \\
\text { Ownership of property }\end{array}$}} & & \multicolumn{4}{|c|}{ Unadjusted } & \multirow{2}{*}{\multicolumn{4}{|c|}{ Adjusted for number of rooms in household }} \\
\hline & & & & & & & & & & \\
\hline Owned & 125 & 100 & $1 \cdot 00$ & & & & $1 \cdot 00$ & & & \\
\hline Rented - council & 6 & 23 & $5 \cdot 00$ & $1 \cdot 85$ & $13 \cdot 52$ & $0 \cdot 002$ & $3 \cdot 78$ & $1 \cdot 21$ & $11 \cdot 85$ & $0 \cdot 022$ \\
\hline Rented - private & 7 & 13 & $2 \cdot 50$ & $0 \cdot 87$ & $7 \cdot 22$ & $0 \cdot 091$ & $1 \cdot 47$ & $0 \cdot 44$ & $4 \cdot 95$ & $0 \cdot 535$ \\
\hline \multicolumn{3}{|c|}{ No. of rooms in household } & \multicolumn{4}{|c|}{ Unadjusted } & \multicolumn{4}{|c|}{ Adjusted for ownership of property } \\
\hline $2-4$ & 13 & 24 & $1 \cdot 00$ & & & & $1 \cdot 00$ & & & \\
\hline 5 & 14 & 31 & $1 \cdot 28$ & $0 \cdot 45$ & 3.69 & 0.642 & $1 \cdot 33$ & $0 \cdot 42$ & $4 \cdot 23$ & $0 \cdot 981$ \\
\hline 6 & 36 & 36 & $0 \cdot 60$ & $0 \cdot 23$ & $1 \cdot 56$ & $0 \cdot 296$ & $0 \cdot 64$ & $0 \cdot 23$ & $1 \cdot 80$ & $0 \cdot 214$ \\
\hline 7 & 28 & 18 & $0 \cdot 38$ & $0 \cdot 12$ & $1 \cdot 14$ & $0 \cdot 085$ & $0 \cdot 41$ & $0 \cdot 12$ & $1 \cdot 37$ & $0 \cdot 153$ \\
\hline $8+$ & 33 & 14 & $0 \cdot 22$ & $0 \cdot 07$ & $0 \cdot 66$ & $0 \cdot 007$ & $0 \cdot 26$ & $0 \cdot 08$ & $0 \cdot 83$ & $0 \cdot 017$ \\
\hline Trend & & & $0 \cdot 67$ & $0 \cdot 55$ & $0 \cdot 81$ & $<0.001$ & $0 \cdot 72$ & $0 \cdot 59$ & $0 \cdot 89$ & $0 \cdot 002$ \\
\hline \multicolumn{11}{|l|}{ Direct risk factors } \\
\hline \multicolumn{3}{|c|}{ Contact with person with IID } & \multicolumn{4}{|c|}{ Unadjusted } & \multicolumn{4}{|c|}{$\begin{array}{l}\text { Adjusted for number of rooms in } \\
\text { household and for ownership of property }\end{array}$} \\
\hline No & 96 & 47 & $1 \cdot 00$ & & & & $1 \cdot 00$ & & & \\
\hline Yes & 43 & 92 & $3 \cdot 45$ & $2 \cdot 10$ & $5 \cdot 68$ & $<0.001$ & $3 \cdot 57$ & $1 \cdot 88$ & $6 \cdot 81$ & $<0.001$ \\
\hline
\end{tabular}

in accommodation with more than five rooms decreased the risk compared to living in less than five rooms, the test for trend being significant. The risk of living in rented accommodation was reduced when adjusted for number of rooms $(\mathrm{OR}=3 \cdot 8$ for council accommodation and $\mathrm{OR}=1.5$ for private accommodation). Some of the risk of rented council housing may be accounted for by having accommodation with fewer rooms. There was an increase in risk associated with contact with another person with gastro-enteritis, not necessarily in the household (OR $=3.5 ; 95 \% \mathrm{CI}$, $2 \cdot 1-5 \cdot 7)$. Adjusting for social class and accommodation had no effect on the risk associated with contact with an ill person (OR $=3 \cdot 6)$. Travel abroad increased the risk, but was not statistically significant; only five cases had travelled abroad (OR $=5.3 ; 95 \%$ CI, 0.33-84.76). The PAF for living in rented council accommodation was $12 \%(95 \% \mathrm{CI}, 2 \cdot 9-15 \cdot 2)$ and the PAF for contact with an ill person was $48 \%(95 \% \mathrm{CI}$, $31-57) .40 \%$ of the cases that arose cannot therefore be explained by these two variables in children under 16 years of age.

\section{Food-borne factors}

No foods were associated with increased risks for rotavirus IID in children under 16 years of age. However reported consumption of salad at home, 
Table 4. Foods which are risk factors for IID with rotavirus in stools in people under 16 years of age, with OR, 95\% CI and P values, univariate, adjusted for accommodation factors and contact with a person with IID

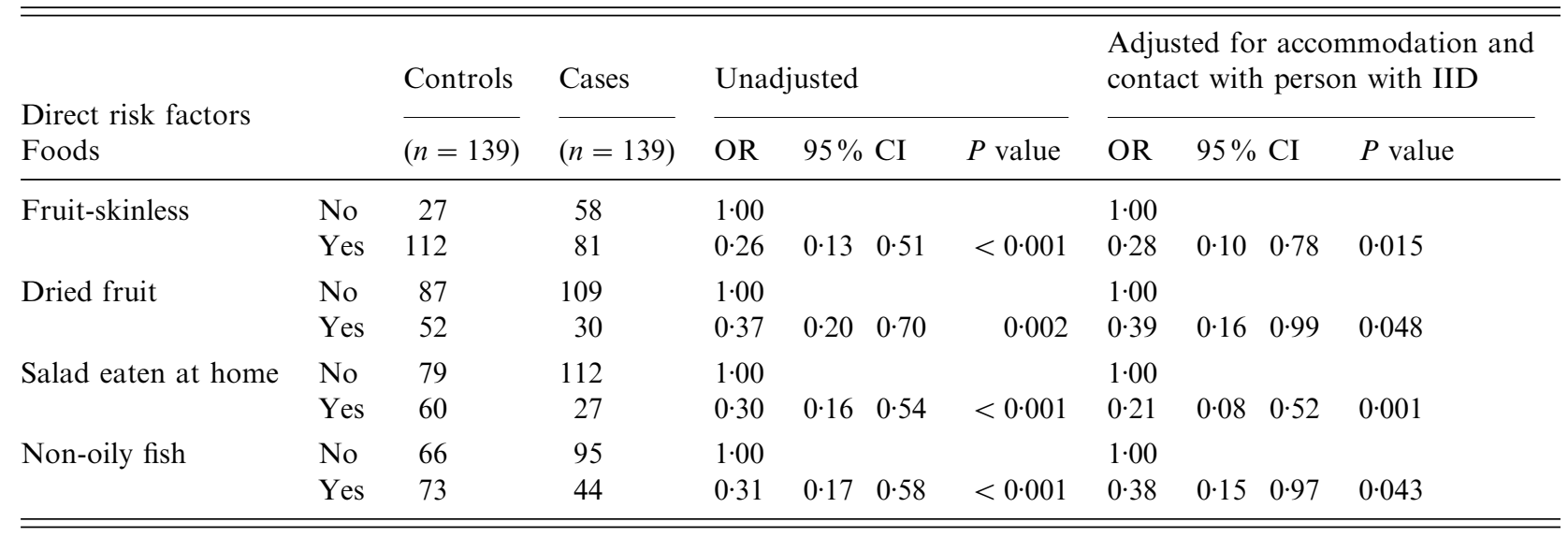

Table 5. Effect of breastfeeding and frequenting nursery or crèche on the risk of developing IID with rotavirus group $A$ in stools in infants under 1 year of age, with odds ratios $(O R), 95 \%$ CI and P values, univariate, adjusted for contact with a person with IID

\begin{tabular}{|c|c|c|c|c|c|c|c|c|c|c|}
\hline \multirow[b]{2}{*}{ Risk factors } & \multirow{2}{*}{$\frac{\text { Controls }}{(n=39)}$} & \multirow{2}{*}{$\frac{\text { Cases }}{(n=39)}$} & \multicolumn{4}{|c|}{ Unadjusted } & \multicolumn{4}{|c|}{$\begin{array}{l}\text { Adjusted for contact } \\
\text { with person with IID }\end{array}$} \\
\hline & & & OR & $95 \%$ & $\mathrm{CI}$ & $P$ value & OR & $95 \%$ & CI & $P$ value \\
\hline \multicolumn{11}{|c|}{ Current infant feeding practice* } \\
\hline Breastfed only & 8 & 1 & $1 \cdot 00$ & & & & $1 \cdot 00$ & & & \\
\hline $\begin{array}{l}\text { Bottle fed with or } \\
\text { without breastfeeding }\end{array}$ & 18 & 36 & $8 \cdot 00$ & $1 \cdot 00$ & 63.96 & $0 \cdot 050$ & $9 \cdot 06$ & $1 \cdot 07$ & $76 \cdot 64$ & $0 \cdot 043$ \\
\hline \multicolumn{11}{|l|}{ Attend nursery/crèche $\dagger$} \\
\hline No & 17 & 16 & $1 \cdot 00$ & & & & & & & \\
\hline Yes & 20 & 15 & $0 \cdot 83$ & $0 \cdot 25$ & $2 \cdot 73$ & 0.763 & & & & \\
\hline \multicolumn{11}{|c|}{ Contact with person with IID } \\
\hline No & 24 & 17 & $1 \cdot 00$ & & & & & & & \\
\hline Yes & 15 & 22 & $1 \cdot 70$ & $0 \cdot 78$ & $3 \cdot 71$ & $0 \cdot 183$ & & & & \\
\hline
\end{tabular}

* Seven controls and 2 cases had a mixed diet including weaning. Missing data for 6 controls.

$\dagger$ Missing data for 2 controls and 8 cases.

skinless fruit, dried fruit and non-oily fish were associated with reduced risk of rotavirus infection of between 50 and $70 \%$ in multivariate analysis adjusted for accommodation factors and contact with a person with IID (Table 4). Significance was at the $0 \cdot 1 \%$ level for consumption of salad at home and at a 1-5\% level for skinless fruit, dried fruit and non-oily fish.

\section{Children under 5 years of age}

In children under 5 years of age, frequenting a nursery or crèche was not a risk factor $(\mathrm{OR}=0.56 ; 95 \% \mathrm{CI}$, 0.29-1·12). There was no significant association after adjusting for accommodation factors $(\mathrm{OR}=0.93$; $95 \%$ CI, 0.34-2.39) or for contact with a person ill with IID $(\mathrm{OR}=0.52 ; 95 \% \mathrm{CI}, 0 \cdot 26-1 \cdot 02, P=0 \cdot 076)$. Data are not presented.

\section{Infants under 1 year}

There was an eightfold increase in the risk of developing rotavirus IID in infants currently being bottle-fed or both breast and bottle-fed in contrast to those who were exclusively breast fed, implying that breast-feeding is protective (Table 5). However the numbers were small with wide confidence intervals and significance is at the 5\% level. Adjustment for contact with a person with IID increased the risk slightly $(\mathrm{OR}=9 \cdot 06 ; 95 \% \mathrm{CI}, 1 \cdot 07-76 \cdot 64)$. The PAF for bottle or mixed feeding compared to breast- 
feeding was $82 \%(95 \%$ CI, 66-91). Attending a crèche or nursery had no statistically significant effect in this age group; there were missing data on eight cases.

\section{DISCUSSION}

This is one of the few studies to describe risk factors for childhood infections with rotavirus, both in the community and presenting to the GP. It has the added advantage of including cases who may not normally have had a stool specimen submitted after consulting their GP. It is, therefore, likely to be more representative of community acquired infection, than results based on routine surveillance and health facilities [9, 11, 13]. Results show that in children under 16 years old, there is a markedly increased risk of rotavirus gastro-enteritis associated with the type of accommodation, in particular rented council housing and housing with less than five rooms, and contact with other people ill with gastro-enteritis. For infants there was a substantially lower risk associated with exclusive breast feeding.

In this study frequenting a crèche or nursery was not a risk factor for children under 5 years old. Similarly this factor was not significant for infants, where an effect may have been expected as this age group has the peak incidence for rotavirus infection. However, the numbers were small and there was missing information on eight cases. This is in contrast to previous findings, where attendance at day care has shown to be a risk factor. For example at a health maintenance organization clinic in Texas, a $2 \cdot 5$-fold increased risk of rotavirus infection was found in association with child care, particularly in the first month of enrolment [9]. In an emergency room setting in Sao Paulo, day care was associated with a sixfold increased risk of rotavirus infection [22]. We did not have information on duration of crèche attendance in our study so could not investigate whether there was increase in risk in the period just after enrolment. Our study included cases that may have had a milder illness as they would not ordinarily have gone to their GP or necessarily have had a stool sample tested. This is in contrast to those exclusively identified in clinical settings [9, 22]. Further, cases in our study were ascertained over a whole year; any markedly seasonal effects may have been diluted, as they would only cause a proportion of cases over the whole year. The time lag between case and control recruitment (median 24 days) may also have contributed to this dilution. It is also possible that levels of hygiene practised in different child care settings vary.

There was a ninefold increase in risk in infants who were bottle fed with or without supplementary breast milk compared to infants who were exclusively breast fed. The results suggest that breast feeding is protective against gastro-enteritis with rotavirus. However, a protective effect of breast feeding has not been consistently found for rotavirus infections, with some population-based studies finding absent or marginal protection [14, 16, 22, 23], whereas a community based study in Egypt found protection [17]. Our study therefore adds to the weight of evidence in favour of the protective effect of breast feeding. The protective effect of breast feeding is thought to be partially mediated through maternal antibodies against rotavirus which are present in breast milk [24], and partly through the specific inhibitory activity of the humanmilk non-antibody glycoconjugates. One such molecule, glycoprotein lactadherin, is secreted in breast milk and prevents rotaviral infection by binding to the rotavirus [18]. The concentration of lactadherin and other inhibitory molecules in breast-milk varies and it has been suggested that this may account for other findings; that breastfeeding appears to confer protection against the symptoms of severe rotavirus infection and that it may postpone rather than prevent severe infection [18, 25, 26]. Another less likely explanation of the finding is that poor hygiene practices lead to contamination of supplemental feeds with rotavirus [27].

It is well-established that different measures of social-deprivation increase the risk of rotavirus infection. Poor maternal education, household crowding, having low birthweight, covered by Medicaid insurance, having been born to unmarried mothers, a maternal age of less than 20 years and maternal smoking have all been found to be associated with rotavirus infection $[11,28]$. Our study looked at a wide range of social deprivation indices (including social class, overcrowding, accommodation, maternal age and marital status), but only the type of accommodation was associated with rotavirus. Although over-crowding was measured, the number of rooms in the household was a better predictor than crowding in the multivariate model; the test for trend was significant with decreased risk as the number of rooms increased. Living in rented council accommodation became less significant when adjusted for the number of rooms, suggesting that some of the effect was mediated through having fewer rooms. The 
increase in risk with contact with persons ill with IID is consistent with current knowledge of transmission of rotavirus which is thought to be through direct contact with infective persons, principally through the faecal oral route [5]. An increased risk was found with travel but this was not significant, which may be because not many travelled.

We investigated whether consumption of various foods was associated with increased risk of rotavirus, treating food as a potential vehicle, given that this has been previously described, albeit rarely [13]. No food was significantly associated with risk of infection. Unexpectedly, we did find a lower risk of disease in children consuming fruits, salads at home and nonoily fish. This finding could be a chance association, or due to multiple testing; however significance for salads eaten at home was at the $0.1 \%$ level, making this unlikely. It could result from residual confounding or bias as children reported as eating these foods, may have a healthier lifestyle or some practice, which was not measured in the questionnaire. Or it could possibly represent a true effect, which is supported by the fact that a similar effect was found over a range of organisms in our study, as reported elsewhere [12]. Were this effect to be true, there are some possible biological mechanisms: these foods contain antioxidants and trace elements [29], which may bolster protection against IID. This has been discussed more fully elsewhere (personal communication: L. C. Rodrigues et al.).

\section{Implications for policy}

Three main findings of this study are relevant for policy: the role of contact with another ill person, housing conditions and the protective effect of breast feeding. Strategies for prevention need to take account of these findings in order to reduce the burden of illness.

A strong risk factor in this study was exposure of children to infected persons, and accounted for $48 \%$ of the infective episodes. Better health education promoting less exposure to a household member or others with diarrhoea could be implemented. This is of particular importance in view of recent findings that rotavirus can be excreted for up to 60 days after an episode of severe illness [30]. Being bottle fed or receiving bottle and breast feeding was associated with a ninefold risk and accounted for $82 \%$ of the episodes in infants. Breastfeeding is already recom- mended and may confer protection not only upon other enteropathogens and respiratory infection, but also against rotavirus. Accommodation with few rooms and rented accommodation increase the risk of rotavirus infection. In view of the delay in assessing the recently developed high titre rhesus rotavirus tetravalent vaccine [3], this study highlights the need for adequate accommodation for children, protecting children from exposure to household members who have diarrhoea and re-emphasizing the importance of breastfeeding.

\section{ACKNOWLEDGEMENTS}

We wish to thank Professor T. W. Meade and the MRC EMCU staff, and Ms M. Goldsborough, Ms A. Williams, Ms L. Hands, Ms E. Marshall, Ms P. Allen, Ms F. Symes, Ms S. Fox and Ms J. Elwood for their invaluable contribution to this study.

We are grateful to the general practices in the MRC's General Practice Research Framework who made this study possible: Backwell, Street, Coleford, Heacham, Todmorden, Ipswich, Abingdon, Whitehaven, Yaxley, Folkestone, Kidderminster, Camberley, Northampton, Sutton-in-Ashfield, Brightlingsea, Biggleswade, Liskeard, Barrow-in-Furness, Ledbury, Henleaze, Widnes, Durham, Walsall, Aston Clinton, Torrington Park, Luton, Darlington, Scunthorpe, St. Johns, Bloomsbury, Ormskirk, Stockport, Atherton, Ampleforth, Bolton, Weymouth, Tewkesbury, Tunbridge Wells, Guildford, Crediton, Tooting, Birmingham, Bournemouth, Stratford upon Avon, Workington, Hull, Fovant, Cradley, Birstall, Richmond, Chapel en le Frith, Bingley, Pinner, Sheffield, Bassingham, Chessington, Temple Fortune, Hampton Wick, Bracknell, East Grinstead, Newcastle, Settle, Fremington, Limehouse, Leeds, Bishop Auckland, Tonbridge, Bromley, Willesden, Beckton.

Membership of the IID Study Executive included: J. S. Brazier, M. M. Brett, D. Brennan, W. Browne, P. E. Cook, J. M. Cowden, P. Cumberland, R. P. Eglin, N. Fasey, S. Gordon-Brown, P. Hayes, M. J. Hudson, V. King, J. M. Kramer, J. Martin, C. Olohan-Bramley, R. J. Owen, J. A. Roberts, P. J. Roderick, L. C. Rodrigues, B. Rowe, D. Sethi, H. R. Smith, M. T. Skinner, R. Skinner, P. N. Sockett, D. S. Tompkins, P. G. Wall, J. G. Wheeler, A. L. Wight.

No author has a commercial or other association that might pose a conflict of interest. Authors were in 
government-funded tenured positions or were supported by a UK Department of Health grant.

\section{REFERENCES}

1. De Zoysya I, Feacham RV. Interventions for the control of diarrhoeal diseases among young children: rotavirus and cholera immunisation. Bull WHO 1985; 63: 569-83.

2. Bern C, Martines J, de Zoysa I, Glass RI. The magnitude of the global problem of diarrhoeal disease: a ten year update. Bull WHO 1992; 70: 705-14.

3. Vesikari T. Rotavirus vaccines against diarrhoeal disease. Lancet 1997; 350: 1538-41.

4. Glass RI, Kilgore PE, Holman RC, et al. The epidemiology of rotavirus diarrhoea in the United States: surveillance and estimates of disease burden. J Infect Dis 1996; 174 (Suppl 1): S5-11.

5. Parashar UD, Bresce JS, Gentsch JR, Glass RI. Rotavirus. Emerg Infect Dis 1998; 4: 561-70.

6. Ryan MJ, Ramsay M, Brown D, Guy NJ, Farrington CP, Wall PJ. Hospital admissions attributable to rotavirus infection in England and Wales. J Infect Dis 1996; 174 (Suppl 1): S12-8.

7. Tompkins DS, Hudson MJ, Smith HR, et al. A study of infectious intestinal disease in England: microbiological findings in cases and controls. Commun Dis Publ Hlth 1992; 2 : 108-13.

8. Liddle JLM, Burgess MA, Gilbert GL, et al. Rotavirus gastro-enteritis: impact on young children, their families and the health care system. MJA 1997; 167: 304-7.

9. Reves RR, Morrow AL, Bartlett AV, et al. Child care increases the risk of clinic visits for acute diarrhea due to rotavirus. Am J Epidemiol 1993; 137: 97-107.

10. Menon S, Santosham M, Reid R, Ameido-Hill J, Sack RB, Comstock GW. Rotavirus diarrhoea in Apache children: a case-control study. Int J Epidemiol 1990; 19: 715-21.

11. Kotloff KL, Wassermann SS, Steciak JY, et al. Acute diarrhea in Baltimore children attending an outpatient clinic. Pediatr Infect Dis J 1988; 7: 753-9.

12. A study of infectious intestinal disease in England. London: The Stationery Office, 2000. In press.

13. Advisory Committee on the Microbiological Safety of Food. Report on food-borne viral infections. London: The Stationery Office, 1998.

14. Golding J, Emmett PM, Rogers IS. Gastro-enteritis, diarrhoea and breast feeding. Early Hum Dev 1997; 49 (Suppl): S83-103.

15. Mitra AK, Rabbani F. The importance of breast feeding in minimizing mortality and morbidity from diarrhoeal disease: the Bangladesh perspective. J Diarrheal Dis Res 1995; 13: 1-7.

16. Gurwith M, Wenman W, Hinde D, Feltham S, Greenberg H. A prospective study of rotavirus infection in infants and young children. J Infect Dis 1981; 144: 218-24.

17. Naficy AB, Abu-Elyazeed R, Holmes JL, et al. Epidemiology of rotavirus diarrhea in Egyptian children and implications for disease control. Am J Epidemiol 1999; 150: 770-7.

18. Newburg DS, Peterson JA, Ruiz-Palacios GM, et al. Role of human-milk lactadherin in protection against symptomatic rotavirus infection. Lancet 1998; 351: $1160-4$.

19. Sethi D, Wheeler JG, Cowden JM, et al. A study of infectious intestinal disease in England: plan and methods of data collection. Commun Dis Publ Hlth 1999; 2 : 101-7.

20. Wheeler JG, Sethi D, Cowden JM, et al. Study of infectious intestinal disease in England: Rates in the community, presenting to GPs and reported to national surveillance. BMJ 1999; 318: 1046-50.

21. Stata Corporation. Stata statistical software. Release 5.0. College Station, TX: Stata Corporation, 1997.

22. Blake PA, Ramos S, MacDonald KL, et al. Pathogenspecific risk factors and protective factors for acute diarrheal disease in urban Brazilian infants. J Infect Dis 1993; 167: 627-32.

23. Gurwith M, Wenman W, Garwith D, Brunton J, Feltham S, Greenberg H. Diarrhoea among infants and young children in Canada: a longitudinal study in three northern communities. J Infect Dis 1983; 147: 685-92.

24. Brussow H, Benitez O, Uribe F, Sidoti J, Rosa K, Cravioto A. Rotavirus inhibitory activity in serial milk samples from Mexican women and rotavirus infections in their children during their first year of life. J Clin Microbiol 1993; 31: 593-7.

25. Haffejee IE, Moosa A. Rotavirus studies in Indian (Asian) South African infants with acute gastroenteritis: II. Clinical aspects and outcome. Ann Trop Paediatr 1990; 10: 245-54.

26. Clemens J, Rao M, Ahmed F, et al. Breast feeding and the risk of life threatening rotavirus diarrhea: prevention or postponement? Pediatrics 1993 ; 92: 680-5.

27. Martines JC, Rea M, De Zoysa I. Breast feeding in the first six months. BMJ 1992; 304: 1068-9.

28. Newman RD, Grupp-Phelan J, Shay DK, Davis RL. Perinatal risk factors for infant hospitalization with viral gastro-enteritis. Pediatrics 1999; 103: E3.

29. Report by the World Cancer Research Fund. Geneva: WHO, 1990.

30. Richardson S, Grimwood K, Gorrell R, Palombo E, Barnes G, Bishop R. Extended excretion of rotavirus after severe diarrhoea in young children. Lancet 1998; 351 : 1844-8. 